\title{
A Study on Factors Related to Hypertensive Disorders in Pregnancy in Ngaoundere (Adamawa Region, Cameroon)
}

\author{
Olivier Pancha Mbouemboue ${ }^{1,2, *}$, Diallo Cellou ${ }^{3}$, Marcel Tangyi Tamanji ${ }^{4,5}$, Chantal Blakga ${ }^{1}$, \\ Armel Herve Nwabo Kamdje ${ }^{1}$, Jacques Olivier Ngoufack ${ }^{2}$, Andre Youmbi ${ }^{3}$ \\ ${ }^{1}$ Department of Biomedical Sciences, Faculty of Science, University of Ngaoundere, Ngaoundere, Cameroon \\ ${ }^{2}$ General Medicine Service, Ngaoundere Regional Hospital, Ngaoundere, Cameroon \\ ${ }^{3}$ Gynaecology and Obstetrics Service, Ngaoundere Regional Hospital, Ngaoundere, Cameroon \\ ${ }^{4}$ Clinical Laboratory Service, Ngaoundere Regional Hospital, Ngaoundere, Cameroon \\ ${ }^{5}$ Faculty of Science, University of Buea, Buea, Cameroon
}

Email address:

olivier_pancha@yahoo.fr(O.P. Mbouemboue)

${ }^{*}$ Corresponding author

To cite this article:

Olivier Pancha Mbouemboue, Diallo Cellou, Marcel Tangyi Tamanji, Chantal Blakga, Armel Herve Nwabo Kamdje, Jacques Olivier Ngoufack, Andre Youmbi. A Study on Factors Related to Hypertensive Disorders in Pregnancy in Ngaoundere (Adamawa Region, Cameroon). Clinical Medicine Research. Vol. 5, No. 2, 2016, pp. 6-12. doi: 10.11648/j.cmr.20160502.11

Received: January 10, 2016; Accepted: February 12, 2016; Published: April 26, 2016

\begin{abstract}
Background: In sub-Saharan Africa, hypertensive disorders in pregnancy remain a major call for concern owing to their increasing incidence, gravity and associated complications. In Cameroon, the epidemiological reality of hypertensive disorders in pregnancy remains unknown in the majority of regions. Objective: This study aimed to identify the determinants of hypertensive disorders among pregnant women in a hospital milieu in Ngaoundere town. Methods: A cross-sectional study was carried out at the Ngaoundere Regional Hospital, the reference hospital facility of the Adamawa Region of Cameroon from May to June 2014. Results: In total, 160 pregnant women were examined during the period of study, among which 75 recorded a high blood pressure thus fulfilling our inclusion criteria. Age $(\mathrm{P}=0.013)$, previous twin pregnancy $(\mathrm{P}=0.013)$ and preeclampsia $(\mathrm{P}=0.013)$ were found to be significantly predictive of chronic hypertension. Religion $(\mathrm{P}=0.004)$ and multiparity $(\mathrm{P}=0.001)$ were identified as significant independent predictive risk factors of preeclampsia, History of preeclampsia $(\mathrm{P}=0.025)$ was identified as predictive risk factor for superimposed preeclampsia. Conclusion: Independent predisposing factors associated with hypertensive disorders in pregnancy in our milieu, which include advanced age, the notion of preeclampsia and history of twin pregnancy for chronic hypertension, parity and religion for preeclampsia, and history of preeclampsia for superimposed preeclampsia.
\end{abstract}

Keywords: Preeclampsia/Eclampsia, Hypertensive Disorders, Pregnancy, Cameroon

\section{Introduction}

Hypertensive disorders during pregnancy result in the occurrence of a heterogeneous group of pathological states with high blood pressure (HBP) in pregnancy being a common factor. According to Zezza and colleagues, these are the major causes of maternal and foetal morbidity and mortality [1]. Hypertensive disorders in pregnancy comprise four main manifestations: chronic high blood pressure, preeclampsia/eclampsia, non-proteinuria gestational high blood pressure and superimposed preeclampsia $[2,3]$. Data from previous literature demonstrates that about $1 \%$ of pregnancies are complicated by a pre-existing hypertension, 5 to $6 \%$ by non-proteinuria gestational hypertension, and 1 to $2 \%$ by preeclampsia [4]. According to WHO, $9.1 \%$ of women develop a preeclampsia or gestational HBP during their pregnancy, with preeclampsia being the most common of the clinical outcomes affecting about 3 to $4 \%$ of all pregnant women in the world [5].

In sub-Saharan Africa, hypertensive disorders in pregnancy remain a major call for concern owing to their 
increasing incidence, gravity and associated complications [6, 7, 8]. In Cameroon, the epidemiological reality of hypertensive disorders in pregnancy remains unknown in the majority of regions.

The lack of epidemiologic data in the Adamawa region of Cameroon and the need to better understand the factors related to hypertensive disorders in pregnancy towards the proposition of evidence-based preventive policies for maternal healthcare in our context, was the rationale of this study, with goal being to identify the determinants of hypertensive disorders among pregnant women in a hospital milieu in Ngaoundere town.

\section{Methodology}

\subsection{Study Area and Population}

The study was monocentric and cross-sectional, carried out at the Ngaoundere Regional Hospital, the reference hospital facility of the Adamawa Region of Cameroon. Adamawa is one of the ten regions of Cameroon having Ngaoundere as its administrative headquarter.

\subsection{Selection Criteria}

The target population was made up of pregnant women resident in the Adamawa region for a minimum of six month. The sampling was randomly and progressively done throughout the study period at the Gynaeco-Obstetric Service of the Ngaoundere Regional Hospital.

Included in this study were hypertensive pregnant women (Systolic BP >140 $\mathrm{mmHg}$ and/or Diastolic BP >90 $\mathrm{mmHg}$ ) who attended these services during the study period.

Pregnant women presenting an obstetric or gynaecologic pathology unconnected to a high blood pressure or a proteinuria without high blood pressure or refused to consent to the study were exclude from this work.

\subsection{Judging Criteria}

The criteria used for the classification of participants under the different types of hypertensive disorders were those described by the Canadian Society of Gynaecologists and Obstetricians $^{3}$ :

\subsection{Variables and Measurements}

\subsubsection{Socio-Demographic and Professional Characteristics}

Age, matrimonial status, area of residence, religion, level of education, ethnicity and profession were collected using a semi-structured questionnaire.

\subsubsection{Blood Pressure}

The blood pressure was measured and interpreted in accordance with the National High Blood Pressure Education Program Working Group on High Blood Pressure in Pregnancy recommendations ${ }^{2}$. This measurement was done with an electronic blood pressure machine (OMRON-HEM-712CN2, Serial number: 64167999LF, USA) in a sitting position, with the armband on the forearm elevated to the heart level. Paired measurements were taken on both the left and right arms with a time difference of 3 to 5 seconds, and the average measurement calculated and recorded. High blood pressure was defined as systolic blood pressure $>140 \mathrm{mmHg}$ and/or diastolic blood pressure $>90 \mathrm{mmHg}$.

\subsubsection{Anthropometric Parameters}

Height and weight measurement of participants were performed using a calibrated weight balance and height scale respectively.

\subsubsection{Proteinuria}

Urine protein detection and semi-quantification was performed on early morning urine samples of all participants using the MEDI-Test COMB II urine test strips.

\subsection{Statistical Methods}

The data collected were registered on the version 4.1 Cs Pro software and transferred on to the SPSS version 20.0 software for data processing and analyses. The descriptive statistic allowed us to determine the frequency of variables as well as the distribution of hypertensive disorders in pregnancy following variables such as socio-demographic, professional, family and medical history, and cardiovascular disease risk factors.

The Chi-square test was used to determine the association between variables and types of hypertensive disorders in pregnancy. Finally, a logistic regression model enabled us to verify the association between risk factors and hypertensive disorders of pregnancy and also permitted to confirm the associations observed in the bivariate analysis. Statistical significance was accepted at $\mathrm{P}<0.05$.

\subsection{Ethical Considerations}

Participants were informed on the nature and interest of the study in the language best understood after which they voluntarily consented to participate in the study in writing. This research work was granted the approval of the Ethic Committee of the Ngaoundere Regional Hospital.

\section{Results}

In total, 160 pregnant women were examined during the study period. Among them, 75 recorded a high blood pressure thus fulfilling our inclusion criteria. Participants' age ranged from 14 to 40 years old with an average of $25.66 \pm 6.17$. 44\% $(n=33)$ of participants were aged between 14 and 24 year old and $14.7 \%(n=11)$ were 35 year old and above. Details of the participant characteristics are presented in Table 1.

Following bivariate analysis, chronic hypertension, was observed to be significantly associated with age $(\mathrm{P}=0.002)$, history of preeclampsia, $(\mathrm{P}=0.004)$ and history of high blood pressure $(\mathrm{P}<0.001)$. Also, gestational hypertension was significantly associated with history of diabetes $(\mathrm{P}=0.01)$ and history of paternal hypertension $(\mathrm{P}=0.04)$. Furthermore, significant associations were recorded between preeclampsia an age $(\mathrm{p}=0.044)$, religion $(\mathrm{P}=0.002)$, ethnicity $(\mathrm{P}=0.027)$, 
parity $(\mathrm{P}<0.001)$, history of hypertension $(\mathrm{P}=0.006)$ and history of paternal hypertension $(\mathrm{P}=0.042)$. Moreover, superimposed preeclampsia was significantly associated with age $\quad(\mathrm{P}=0.016), \quad$ occupation $\quad(\mathrm{P}=0.002)$, history of preeclampsia $(\mathrm{P}=0.005)$ and history of high blood pressure $(\mathrm{P}<0.001)$ (Table 2).

Results of multivariate analysis of results are shown in Table 3.

Table 1. Distribution of Participants by Sociodemographic Characteristic and Type of Hypertensive Disorders.

\begin{tabular}{|c|c|c|c|c|c|c|c|c|c|c|}
\hline \multirow{2}{*}{ VARIABLES } & \multicolumn{2}{|c|}{ ALL } & \multicolumn{2}{|c|}{ C-HT ${ }^{1}$} & \multicolumn{2}{|c|}{$\mathrm{G}^{-\mathrm{HT}^{2}}$} & \multicolumn{2}{|c|}{$\mathbf{P E}^{3}$} & \multicolumn{2}{|c|}{ S-PE ${ }^{4}$} \\
\hline & $\mathbf{N}$ & $\%$ & $\mathbf{N}$ & $\%$ & $\mathbf{N}$ & $\%$ & $\mathbf{N}$ & $\%$ & $\mathbf{N}$ & $\%$ \\
\hline \multicolumn{11}{|l|}{ Age } \\
\hline 14-19 & 12 & $(16,0)$ & 1 & $(8,3)$ & 1 & $(8,3)$ & 10 & $(83,3)$ & 0 & $(0,0)$ \\
\hline $20-24$ & 21 & $(28,0)$ & 3 & $(14,3)$ & 6 & $(28,6)$ & 12 & $(57,1)$ & 0 & $(0,0)$ \\
\hline $25-29$ & 23 & $(30,6)$ & 2 & $(8,7)$ & 6 & $(26,1)$ & 10 & $(43,5)$ & 5 & $(21,7)$ \\
\hline $30-34$ & 08 & $(10,7)$ & 3 & $(37,5)$ & 2 & $(25,0)$ & 2 & $(25,0)$ & 1 & $(12,5)$ \\
\hline \multicolumn{11}{|l|}{ Marital Status } \\
\hline Single & 14 & $(18,7)$ & 5 & $(35,7)$ & 3 & $(21,5)$ & 5 & $(35,7)$ & 1 & $(7,1)$ \\
\hline \multicolumn{11}{|l|}{ Area of Residence } \\
\hline Rural & 15 & $(20,0)$ & 1 & $(6,7)$ & 5 & $(33,3)$ & 7 & $(46,7)$ & 2 & $(13,3)$ \\
\hline Urban & 60 & $(80,0)$ & 14 & $(23,3)$ & 11 & $(18,3)$ & 28 & $(46,7)$ & 7 & $(11,7)$ \\
\hline \multicolumn{11}{|l|}{ Religion } \\
\hline Catholic & 19 & $(26,3)$ & 8 & $(42,1)$ & 4 & $(21,1)$ & 4 & $(21,1)$ & 3 & $(15,7)$ \\
\hline Others & 3 & $(4,0)$ & 1 & $(33,3)$ & 1 & $(33,3)$ & 1 & $(33,3)$ & 0 & $(0,0)$ \\
\hline \multicolumn{11}{|l|}{ Level of Education } \\
\hline Illiterate & 16 & $(21,3)$ & 3 & $(18,7)$ & 2 & $(12,5)$ & 9 & $(56,3)$ & 2 & $(12,5)$ \\
\hline Primary & 19 & $(25,3)$ & 4 & $(21,1)$ & 4 & $(21,1)$ & 9 & $(47,3)$ & 2 & $(10,5)$ \\
\hline Secondary & 28 & $(37,3)$ & 5 & $(17,9)$ & 6 & $(21,4)$ & 12 & $(42,8)$ & 5 & $(17,9)$ \\
\hline Higher & 12 & $(16,0)$ & 3 & $(25,0)$ & 4 & $(33,3)$ & 5 & $(41,7)$ & 0 & $(0,0)$ \\
\hline \multicolumn{11}{|l|}{ Ethnicity } \\
\hline Fulani & 26 & $(34,7)$ & 3 & $(11,6)$ & 6 & $(23,0)$ & 14 & $(53,8)$ & 3 & $(11,6)$ \\
\hline Mboum & 8 & $(10,6)$ & 1 & $(12,5)$ & 1 & $(12,5)$ & 5 & $(62,5)$ & 1 & $(12,5)$ \\
\hline Gbaya & 5 & $(6,7)$ & 2 & $(40,0)$ & 1 & $(20,0)$ & 1 & $(20,0)$ & 1 & $(20,0)$ \\
\hline Bamileke & 7 & $(9,3)$ & 1 & $(14,3)$ & 3 & $(42,8)$ & 3 & $(42,8)$ & 0 & $(0,0)$ \\
\hline Dii & 3 & $(4,0)$ & 1 & $(33,3)$ & 0 & $(0,0)$ & 0 & $(0,0)$ & 2 & $(66,7)$ \\
\hline Others & 26 & $(34,7)$ & 7 & $(26,9)$ & 5 & $(19,2)$ & 12 & $(46,2)$ & 2 & $(7,7)$ \\
\hline \multicolumn{11}{|l|}{ Occupation } \\
\hline Student & 16 & $(21,3)$ & 3 & $(18,8)$ & 6 & $(37,5)$ & 7 & $(43,7)$ & 0 & $(0,0)$ \\
\hline Informal Sector & 13 & $(17,3)$ & 5 & $(38,4)$ & 2 & $(15,4)$ & 2 & $(15,4)$ & 4 & $(30,8)$ \\
\hline
\end{tabular}

${ }^{1}$ C-HT: Chronic Hypertension; ${ }^{2}$ G-HT: Gestational Hypertension; ${ }^{3}$ PE: Preeclampsia; ${ }^{4}$ S-PE: Superimposed Preeclampsia

Table 2. Association between Studied Variables and Hypertensive Disorders.

\begin{tabular}{|c|c|c|c|c|c|c|c|c|c|c|c|c|}
\hline \multirow{2}{*}{ VARIABLES } & \multicolumn{3}{|c|}{$\mathrm{C}^{-\mathrm{HT}^{1}}(\mathrm{~N}=15)$} & \multicolumn{3}{|c|}{$G-\mathrm{HT}^{2}(\mathrm{~N}=16)$} & \multicolumn{2}{|c|}{$\mathrm{PE}^{3}(\mathrm{~N}=35)$} & \multicolumn{4}{|c|}{${\mathrm{S}-P E^{4}(\mathrm{~N}=9)}$} \\
\hline & Value & df & P value & Value & df & P value & Value & df & P value & Value & df & P value \\
\hline Age & 16,582 & 4 & 0,002 & 2,247 & 4 & 0,69 & 9,779 & 4 & 0,044 & 12,207 & 4 & 0,016 \\
\hline Marital Status & 3,196 & 1 & 0,074 & 0,045 & 1 & 0,833 & 0,214 & 1 & 0,644 & 0,226 & 1 & 0,635 \\
\hline Type of Marriage & 1,587 & 1 & 0,208 & 3,467 & 1 & 0,063 & 0,262 & 1 & 0,609 & 0,844 & 1 & 0,358 \\
\hline Area of Residence & 1,008 & 1 & 0,315 & 3,292 & 1 & 0,070 & 0,650 & 1 & 0,587 & 0,315 & 1 & 0,575 \\
\hline Religion & 7,049 & 3 & 0,070 & 0,209 & 3 & 0,976 & 14,866 & 3 & 0,002 & 0,722 & 3 & 0,868 \\
\hline Level of Education & 0,728 & 3 & 0,867 & 0,293 & 3 & 0,961 & 5,437 & 3 & 0,142 & 2,891 & 3 & 0,409 \\
\hline Ethnicity & 1,985 & 5 & 0,851 & 3,619 & 5 & 0,605 & 12,684 & 5 & 0,027 & 7,611 & 5 & 0,177 \\
\hline Occupation & 4,935 & 6 & 0,552 & 5,443 & 6 & 0,488 & 8,089 & 6 & 0,232 & 20,758 & 6 & 0,002 \\
\hline Parity & 2,321 & 2 & 0,313 & 0,41 & 2 & 0,815 & 15,474 & 2 & 0,000 & 3,847 & 2 & 0,146 \\
\hline History of twin Pregnancy & 0,424 & 4 & 0,515 & 0,456 & 1 & 0,500 & 0,023 & 1 & 0,878 & 2,901 & 1 & 0,089 \\
\hline History of Preeclampsia & 11,096 & 2 & 0,004 & 0,578 & 2 & 0,749 & 1,154 & 2 & 0,562 & 10,585 & 2 & 0,005 \\
\hline History of Hypertension & 74,213 & 2 & 0,001 & 3,292 & 2 & 0,193 & 10,203 & 2 & 0,006 & 59,819 & 2 & 0,001 \\
\hline History of Diabetes & 0,21 & 2 & 0,901 & 9,156 & 2 & 0,010 & 3,863 & 2 & 0,145 & 0,121 & 2 & 0,941 \\
\hline Hypertensive Mother & 2,66 & 2 & 0,264 & 4,262 & 2 & 0,119 & 3,725 & 2 & 0,155 & 1,047 & 2 & 0,593 \\
\hline Hypertensive Father & 1,183 & 2 & 0,554 & 6,453 & 2 & 0,040 & 6,345 & 2 & 0,042 & 2,490 & 2 & 0,288 \\
\hline Alcohol Consumption & 0,893 & 1 & 0,345 & 0,191 & 1 & 0,662 & 3,448 & 1 & 0,063 & 0,774 & 1 & 0,379 \\
\hline
\end{tabular}


Olivier Pancha Mbouemboue et al: : A Study on Factors Related to Hypertensive Disorders in Pregnancy in

Ngaoundere (Adamawa Region, Cameroon)

Table 3. Predictive Factors of Hypertensive Disorders (Multivariate Analysis)

\begin{tabular}{|c|c|c|c|c|c|c|c|c|}
\hline \multirow{2}{*}{ VARIABLES } & \multicolumn{2}{|l|}{$\mathrm{C}-\mathrm{HT}^{1}$} & \multicolumn{2}{|l|}{ G-HT ${ }^{2}$} & \multicolumn{2}{|l|}{$\mathbf{P E}^{3}$} & \multicolumn{2}{|l|}{ S-PE ${ }^{4}$} \\
\hline & Odds Ratio & Pvalue & Odds Ratio & Pvalue & Odds Ratio & Pvalue & Odds Ratio & Pvalue \\
\hline Age & & & & 0,722 & & 0,075 & & 0,797 \\
\hline $14-19$ & Ref. & 0,013 & Ref & & Ref & & 0,000 & \\
\hline $20-24$ & 1,833 & & 3,130 & & 0,450 & & 0,000 & \\
\hline $25-29$ & 1,048 & & 3,892 & & 0,455 & & Ref & \\
\hline $30-34$ & 6,600 & & 2,286 & & 0,143 & & 0,345 & \\
\hline 35 et + & 13,20 & & 1,500 & & 0,094 & & 1,629 & \\
\hline Marital Status & & 0,084 & & 0,833 & & 0,644 & & 0,638 \\
\hline Single & Ref. & & Ref & & Ref & & Ref & \\
\hline Married & 0,358 & & 0,867 & & 1,282 & & 1,664 & \\
\hline Area of Residence & & 0,335 & & 0,079 & & 0,422 & & 0,578 \\
\hline Rural & Ref. & & Ref & & Ref & & Ref & \\
\hline Urban & 2,777 & & 0,355 & & 0,673 & & 0,629 & \\
\hline Religion & Ref. & 0,111 & & 0,976 & & 0,004 & & 0,986 \\
\hline Catholic & 0,121 & & Ref & & Ref & & Ref & \\
\hline Protestant & 0,313 & & 0,864 & & 1,187 & & 0,765 & \\
\hline Muslim & 0,531 & & 1,169 & & 5,255 & & 0,754 & \\
\hline Others & & & 1,187 & & 1,187 & & 0,000 & \\
\hline Level of Education & Ref. & 0,869 & & 0,962 & & 0,158 & & 0,982 \\
\hline Illiterate & 0,903 & & Ref & & Ref & & Ref & \\
\hline Primary & 0,574 & & 1,419 & & 0,577 & & 0,667 & \\
\hline Secondary & 0,656 & & 1,100 & & 0,370 & & 0,902 & \\
\hline Higher & & & 1,419 & & 0,278 & & 0,000 & \\
\hline Ethnicity & Ref. & 0,869 & & 0,804 & & 0,127 & & 0,439 \\
\hline Peulh & 1,750 & & Ref & & Ref & & Ref & \\
\hline Mboum & 3,500 & & 0,813 & & 2,768 & & 1,750 & \\
\hline Gbaya & 0,933 & & 0,722 & & 0,246 & & 1,556 & \\
\hline Bamileke & 1,750 & & 1,500 & & 0,511 & & 0,000 & \\
\hline Dii & 1,531 & & 0,000 & & 0,000 & & 4,000 & \\
\hline Others & & & 0,492 & & 0,450 & & 0,406 & \\
\hline Occupation & Ref & 0,620 & & 0,631 & & 0,107 & & 0,641 \\
\hline Student & 0,958 & & Ref & & Ref & & 0,000 & \\
\hline Housewife & 0,872 & & 0,599 & & 1,714 & & Ref & \\
\hline Salary Earner & 2,099 & & 0,000 & & 1,714 & & 1,404 & \\
\hline Informal Sector & & & 0,344 & & 0,286 & & 2,607 & \\
\hline Parity & Ref & 0,330 & & 0,816 & & 0,001 & & 0,225 \\
\hline 0 & 1,548 & & Ref & & Ref & & Ref & \\
\hline 1 & 2,560 & & 0,726 & & 0,166 & & 6,484 & \\
\hline$\geq 2$ & & & 0,708 & & 0,236 & & 6,321 & \\
\hline History of twin Pregnancy & Ref & 0,013 & & 0,999 & & 0,878 & & 0,133 \\
\hline Yes & 0,131 & & 0,000 & & Ref & & Ref & \\
\hline No & & & Ref. & & 0,836 & & 0,162 & \\
\hline History of Preeclampsia & Ref & 0,013 & & 0,761 & & 0,590 & & 0,025 \\
\hline Yes & 0,131 & & Ref & & Ref & & Ref & \\
\hline No & 0,438 & & 1,077 & & 2,973 & & 0,116 & \\
\hline Do not know & & & 2,50 & & 2,500 & & 0,000 & \\
\hline Hypertensive Mother & Ref & 0,282 & & 0,137 & & 0,171 & & 0,973 \\
\hline Yes & 0,413 & & Ref & & Ref & & Ref & \\
\hline No & 0,369 & & 0,343 & & 0,707 & & 1,213 & \\
\hline Do not know & & & 0,306 & & 2,074 & & 0,000 & \\
\hline Hypertensive Father & Ref & 0,563 & & 0,141 & & 0,056 & & 0,521 \\
\hline Yes & 0,532 & & Ref & & Ref & & Ref & \\
\hline No & 0,411 & & 0,324 & & 1,468 & & 0,429 & \\
\hline Do not know & & & 0,000 & & 5,031 & & 0,000 & \\
\hline Alcohol Consumption & Ref & 0,354 & & 0,663 & & 0,072 & & 0,394 \\
\hline Yes & 2,068 & & Ref. & & Ref & & Ref & \\
\hline No & & & 1,339 & & 2,780 & & 2,504 & \\
\hline
\end{tabular}

${ }^{1}$ C-HT: Chronic Hypertension; ${ }^{2}$ G-HT: Gestational Hypertension; ${ }^{3}$ PE: Preeclampsia; ${ }^{4}$ S-PE: Superimposed Preeclampsia

\section{Discussion}

Several studies have been carried out in the past to identify the risk factors associated with hypertensive disorders of pregnancy $[8,9,10,11]$, however, just a few of such studies permit the prediction of risk factors associated with each type of hypertensive disorder in pregnancy in the same sample population.

The results of this work carried out on 75 pregnant women with hypertension enabled us to isolate the risk factors 
associated with each type of pregnancy-related hypertension in our context.

\subsection{Age}

Preeclampsia accounted for $66.7 \%$ of young parturient participants (14 - 19 and $20-24$ years) although the association between young age and preeclampsia was not significant thus contradicting previous reports $[9,12]$. These results are close to the $68.4 \%$ rate reported by Buambobamanga et $a l$. in a retrospective Congolese study [13]. The results however, differ from those of Zenebe's et al. that highlighted a high rate of hypertensive parturient in the 25 to 34 age group (52.5\%) [8].

Older parturient participants ( $\geq 35$ years old) made up the majority of patients (40\%) suffering from chronic hypertension. Following multivariate analysis, the risk of chronic hypertension increased with age $(\mathrm{P}=0.013$ : $\mathrm{OR}=13.20)$. These results concur with current literature [14, $15,16]$. According to these authors, this alteration may be due to the progressive decrease in nitric oxide excretion and the occurrence of oxidative stress at the origin of an endothelial dysfunction which may be considered as a precocious indicator of atherothrombotic damage and cardiovascular events. Also, Taddei et al. suggested that advanced age is associated with endothelial dysfunction in both pregnant women with normal blood pressure and essential hypertension [17]. Moreover, several varying findings on the role of age as a risk factor to hypertensive disorders in pregnancy have been reported, with younger age being an associated risk factor to preeclampsia/eclampsia on one hand $[9,12]$ and advanced age ( $\geq 30$ years old) on the other $[18,19]$.

\subsection{Marital Status}

The majority of study participants (83.1\%) were married, results which are close to those reported by Tebeu et $a$ l. in a Cameroonian case-control study with $95 \%$ of participants being married [9]. However, these figures differ from the $52 \%$ reported by Mboudou et al. [20]. This high frequency of married women can be explained by the customs and beliefs of this region of Cameroon. Although the majority of parturient participants with high blood pressure were married, no association between marital status and any of the hypertensive disorders in pregnancy was recorded.

\subsection{Area of Residence}

In our study, we noticed a high proportion of hypertensive pregnant women living in urban areas $(80 \%)$. This result differs from that of Zenebe et al. who reported that the proportion of hypertensive parturient favoured rural dwellers (56.5\%) [8]. Our findings most probably stem from several factors including cultural, economic and geographic, favouring inaccessibility to hospital facilities. Also, we can assume that access to the study site was easier for urban than rural dwellers owing to its urban location.

Even though our results did not permit us to conclude on the link between the area of residence and hypertensive disorders in pregnancy, many studies suggest a significant association between the area of residence and gestational blood pressure [8, 21].

\subsection{Ethnicity}

The Fulani ethnic group represented the most part of our sample $(34.7 \%)$, this owing to the fact that they are one of several indigenous ethnic groups in the Adamawa Region. Our results further show a significant association between ethnic group and preeclampsia $(\mathrm{P}=0.027)$. However, ethnicity fails in this study to be reported as a strong determinant of hypertensive disorders in pregnancy as the Fulani ethnicity being over represented in the study population was not taken into account at the beginning of the study, thus a possible source of bias.

\subsection{Religion}

The majority of our hypertensive parturient $(57.3 \%)$ were of the Muslim religion which is in line with the $64.4 \%$ observed by Zenebe et al. in Ethiopia [8]. This can be explained by the fact that the study was carried out in a region of Cameroon where the Muslim religion is most geographically widespread. From the results obtained following multivariate analysis, it was observed that Muslim women were more predisposed to preeclampsia compared to Catholics $(\mathrm{P}=0.004$ : $\mathrm{OR}=5.225)$. This may be in part influenced by the style of life derived from this religion. Interestingly, results from a Norwegian study by Sorensen and colleagues demonstrated that there could be association between religious attendance and blood pressure [22].

\subsection{Education Level}

Participants with secondary school level of education were the most predominant (37.3\%) in this study. This is close to the $43 \%$ recorded by Mboudou et al. in another Cameroonian study [20], but inferior to the $72.4 \%$ observed by Harioly et al. in a Malagasy study [23]. The high prevalence of participants with a low level of education observed in our work can be explained by the high frequency of early marriages in this part of Cameroon, which obliges the young halt education and focus on their matrimonial responsibilities.

Although we found no significant link between level of education and hypertensive disorders in pregnancy, recent studies carried out in Cameroon [9] and Ghana [24] demonstrated significant associations between educational level and hypertensive disorders in pregnancy. This disparity in outcomes may probably be due to the differences in study designs and methodology.

\subsection{Occupation}

In line with our results portraying occupation as a determinant of superimposed preeclampsia $(\mathrm{P}=0.002)$, many surveys reported a significant associations between profession and hypertensive disorders in pregnancy [24, 25], 
although multivariate analyses did not permit us to confirm this link.

\subsection{Parity}

The majority of our pre-eclamptic patients were primiparae $65.8 \%$, which is close to the $68.4 \%$ observed in a Congolese study [13] and likewise a study by Mboudou et al [20].

Compared to the primiparae, multiparous participants demonstrated a low risk to preeclampsia/eclampsia $(\mathrm{P}=0.001$; $\mathrm{OR}=0.236$ ). Many studies have confirmed the place of primiparity as a significant risk factor associated with preeclampsia/eclampsia in Africa, Asia and Europe respectively $[9,10,26]$.

\subsection{Twin Pregnancy}

History of twin pregnancy was a risk factor observed to be associated with chronic hypertension $(\mathrm{P}=0.013)$. This finding corroborates with those of the previous studies in which the risk of gestational hypertension was 2 to 3 times higher in women with a history of twin delivery compared to those with mono-foetal pregnancy [27, 28, 29].

\subsection{History of Preeclampsia}

The prevalence of chronic hypertension was higher among women with a history of preeclampsia in this study, concurring with the findings of Oyati et al. where parturient women presenting preeclampsia/eclampsia constituted a high risk group for developing long term chronic hypertension [30].

Furthermore, preeclampsia was associated with superimposed preeclampsia $(\mathrm{p}=0.025)$, with parturient women without a history of preeclampsia being less predisposed to superimposed preeclampsia. According to Assis et al., the risk of developing hypertension related to pregnancy is higher for women who had already suffered from hypertension during a previous pregnancy [31]. Furthermore, a recent report demonstrates that there is a significant link between history preeclampsia and superimposed preeclampsia [32].

\section{Study Limitations and Implication for Future Research}

Considering in particular the reduced sample size and the uneven distribution of participants between the types of hypertensive disorders, strong associations between predictive variables and types of hypertensive disorders are subject to variations. More so, given the fact that this study was carried out in only one geographical region and spanning a short period of time, inferences cannot be made to the other regions of the country owing to variations in educational awareness, cultural and socioeconomic characteristics to name a few, thus the need for a multicentric study involving the different regions of Cameroon.

\section{Conclusion}

Preeclampsia represents the most frequently encountered form of hypertensive disorders among pregnant women in our environment. In this study, we have also been able to significantly establish evidence of independent predisposing factors associated with hypertensive disorders in pregnancy in a Cameroonian hospital milieu, which include advanced age, the notion of preeclampsia and history of twin pregnancy for chronic hypertension, parity and religion for preeclampsia, and history of preeclampsia for superimposed preeclampsia.

Family history of hypertension, history of diabetes, ethnicity and occupation were also observed to represent contributing risk factors to hypertensive disorders in our study.

\section{Authors' Contributions}

OPM conceived the study and wrote report; CB and JON participated in data collection, data entry, analysis and discussion; OPM, DC, MTT supervised and provided direction for the study, reviewed study report for submission and publication; AHNK and AY also finalized the revision of the paper for submission. All authors approved the revised manuscript.

\section{Conflict of Interest}

There is no conflict of interest in this research study.

\section{Acknowledgments}

Authors wish to thank Dr Adonis Koona Koona for the comments on the manuscript.

\section{References}

[1] Zezza L, Ralli E, Conti E, Passerini J, Autore C, Caserta D. Hypertension in pregnancy. Minerva Gynecol 2014; 66(1): 103-26.

[2] Report of the National High Blood Pressure Education Program Working Group on High Blood Pressure in Pregnancy. Am J Obstet Gynecol 2000; 183(1): S1-S22.

[3] Magee L, Helewa M, Moutquin J, van Dadelszen P, Committee ftHG. Diagnosis, evaluation, and management of the hypertensive disorders of pregnancy. Society of Obstetricians and Gyneacologists of Canada Clinical Practice Guideline, No. 206. J Obstet Gynaecol Can 2008; 30: S1-S48.

[4] Waugh JJ, Bell SC, Kilby MD, Blackwell CN, Seed P, Shennan AH et coll. "Optimal bedside urinalysis for the detection of proteinuria in hypertensive pregnancy: a study of diagnostic accuracy», BJOG 2005; 112(4): 412-417.

[5] Villar J, Carroli G, Wojdyla D, Abalos E, Giordano D, Ba'aqeel H, et al. World Health Organization Antenatal Care Trial Research Group. Preeclampsia, gestational hypertension and intrauterine growth restriction, related or independent conditions? Am J Obstet Gynecol 2006; 194(4): 921-931. 
[6] OMS/AFRO, SAGO, UNFPA. Hypertension artérielle et grossesse in Recommandations pour la pratique clinique des soins obstétricaux et néonataux d'urgence en Afrique: Guide du prestataire. Publication OMS/AFRO. 2009; 27-43.

[7] Moodey J. Maternal death associated with hypertensive disorders of pregnancy: A population based study. Hypertension in pregnancy 2005; 23: 247-256.

[8] Zenebe W, Segni H, Woldie M. Hypertension disorders of pregnancy in Jimma University Specialized Hospital. Ethiop J Health Sci 2011; 21(3).

[9] Tebeu P. M, Foumane P, Mbu R, Fosso G, Biyaga T. P, Fomulu J. N. Risk Factors for Hypertensive Disorders in Pregnancy: A Report from the Maroua Regional Hospital, Cameroon. J Reprod Infertil 2011; 12(3): 227-234.

[10] Bilano VL, Ota E, Ganchimeg T, Mori R, Souza JP. Risk Factors of Pre-Eclampsia/Eclampsia and Its Adverse Outcomes in Low- and Middle-Income Countries: A WHO Secondary Analysis. PLoS One 2014; 9(3): e91198.

[11] Kiondo P, Wamuyu-Maina G, Bimenya GS, Tumwesigye NM, Wandabwa $\mathbf{J}$ and Okong P Risk factors for pre-eclampsia in Mulago Hospital, Kampala, Uganda. Tropical Medicine and International Health 2012; 17 (4): 480-487.

[12] Macdonald-Wallis C, Lawlor DA, Heron J, Fraser A, Nelson SM, et al. Relationships of Risk Factors for Pre-Eclampsia with Patterns of Occurrence of Isolated Gestational Proteinuria during Normal Term Pregnancy. PLoS One 2011; 6(7): e22115.

[13] Buambo-Bamanga SF, Ngbale R, Makoumbou P, Ekoundzola JR. L'éclampsie au centre hospitalier et universitaire de Brazzaville, Congo. Clinics in Mother and Child Health. 2009; 6 (2): 1129-1133.

[14] Lynn M. M, Swamy K. G, Edwards S, Maxson P, Gelfand A et James S. Disparities in maternal hypertension and pregnancy outcomes: Evidence from North Carolina, 1994-2003. Public Health Report 2010; Jul-Aug; 125(4): 579-587.

[15] Bateman BT, Shaw KM, Kuklina EV, Callaghan WM, Seely EW, Hernández-Díaz S. Hypertension in Women of Reproductive Age in the United States: NHANES 1999-2008. PLoS One 2012; 7(4): e36171.

[16] Nakimuli A, Elliott AM, Kaleebu P, Moffett A, Mirembe F (2013) Hypertension Persisting after Pre-Eclampsia: A Prospective Cohort Study at Mulago Hospital, Uganda. PLoS One 2013; 8(12): e85273.

[17] Taddei S, Virdis A, Ghiadoni L, Versari D, Salvetti A. Endothelium, aging, and hypertension. Curr Hypertens Rep. 2006; 8: 84-89.

[18] Alves E, Azevedo A, Rodrigues T, Santos AC, Barros H. Impact of risk factors on hypertensive disorders in pregnancy, in primiparae and multiparae. Ann Hum Biol. 2013; 40(5): 377-84.

[19] Luealon P, Phupong V. Risk factors of preeclampsia in Thai women. J Med Assoc Thai. 2010; 93(6): 661-6.

[20] Mboudou ET, Foumane P, Belley Priso E, Dohbit J, Ze
Minkande J, Nkengafac WM et al. Hypertension au cours de la grossesse: Aspects cliniques et épidémiologiques à l'Hôpital Gynéco-Obstétrique et Pédiatrique de Yaoundé, Cameroun. Clinics in Mother and Child Health 2009; 6(2)1087-93.

[21] Teklu S, Gaym A. Prevalence and clinical correlates of the hypertensive disorders of pregnancy at Tikur Anbessa Hospital, Addis Ababa, Ethiopia. Ethiop Med J 2006; 44(1): $17-26$

[22] Sørensen T, Danbolt LJ, Lien L, Koenig HG, Holmen J. The relationship between religious attendance and blood pressure: the HUNT Study, Norway. Int J Psychiatry Med 2011; 42(1): 13-28.

[23] Harioly NMOJ, Rasolonjatovo TY, Andrianirina M, Randriambololona DMA, Ranoaritiana DB, Andrianjatovo JJ, Randriamiarana JM. Profil épidémiologique des prééclampsies et des éclampsies admises à la réanimation des adultes de la maternité de Befelatanana. Revue d'AnesthésieRéanimation et de Médecine d'Urgence 2009; 1(3): 22-24.

[24] Van Middendorp D, Tensbroek A, Yaw Bio F, Edusei A, Meijjer L, Newton $\mathrm{S}$ et al. Rural and urban differences in blood pressure and pregnancy-induced hypertension among pregnant women in Ghana. Globalization and Health. 2013; 9: 59 .

[25] Ndaboine EM, Kihunrwa A, Rumanyika R, Im HB et Massinde AN. Maternal and Perinatal Outcomes among Eclamptic Patients Admitted to Bugando Medical Centre, Mwanza, Tanzania. African Journal of Reproductive Health 2012; 16(1): 35 .

[26] Reyes Laura M, Garcia Ronald G, Ruiz Silvia L, Camacho Paul A, Ospina Maria B, Aroca Gustavo et al. Risk Factors for Preeclampsia in Women from Colombia: A Case-Control Study. PLoS One. 2012; 7(7): e41622.

[27] Duckitt K, Harrington D. Risk factors for pre-eclampsia at antenatal booking: systematic review of controlled studies. $B M J$ 2005; 330: 565-567.

[28] Ye C, Ruan Y, Zou L, Li G, Li C, Chen Y et al. The 2011 Survey on Hypertensive Disorders of Pregnancy (HDP) in China: Prevalence, Risk Factors, Complications, Pregnancy and Perinatal Outcomes. PLoS One 2014; 9(6): e100180.

[29] Chittacharoen A, Wetchapruekpitak S, Suthutvoravut S. Pregnancy induced hypertension in twin pregnancy. $J$ Med Assoc Thai 2005; 88 (Suppl 2): S69-74.

[30] Oyati AI, Danbauchi SS, Isa MS, Alhassan MA, Sani BG, Anyiam CA et al. Role of pre-eclamptic toxaemia or eclampsia in hypertensive women attending cardiac clinic of Ahmadu Bello University teaching hospital Zaria, Nigeria. Annals of African Medicine 2008; 7(3): 133-137.

[31] Assis TR, Viana FP, Rassi S. Study on the major maternal risk factors in hypertensive syndromes. Arq Bras Cardiol 2008; 91(1): 11-7.

[32] Lecarpentier E, Tsatsaris V, Goffinet F, Cabrol D, Sibai B, Haddad Bassam. Risk Factors of Superimposed Preeclampsia in Women with Essential Chronic Hypertension Treated before Pregnancy. PLoS One 2013; 8(5): e62140. 